\title{
CONSTRUCCIÓN COLECTIVA DE POLÍTICAS \\ PÚBLICAS PARA EL DESARROLLO HUMANO SOSTENIBLE ${ }^{1}$
}

\author{
LINA MARÍA ZULUAGA GIRALDO \\ JEMAY MOSQUERA TÉLLEZ ${ }^{3}$ \\ ELKIN RAÚL GÓMEZ CARVAJAL ${ }^{4}$ \\ JAVIER FRANCISCO PEÑALOSA OTERO ${ }^{5}$
}

Recibido el 12 de junio de 2012 y aprobado el 5 de
septiembre de 2012

\section{RESUMEN}

El trabajo es resultado de un proceso prospectivo y estratégico de acompañamiento y empoderamiento local en 10 municipios de Norte de Santander, tendiente a identificar sus ventajas comparativas y proponer su transformación en ventajas competitivas, para formular visiones subregionales de desarrollo humano sostenible, bajo criterios participativos e incluyentes de grupos tradicionalmente segregados, como mujeres y jóvenes, mediante las cuales se puedan configurar espacios de integración subregional para asegurar un desarrollo endógeno y sinérgico del territorio.

\section{PALABRAS CLAVE:}

Planeación participativa, prospectiva estratégica, desarrollo humano sostenible, políticas públicas, integración regional.

\section{COLLECTIVE CONSTRUCTION OF PUBLIC POLICIES FOR SUSTAINABLE HUMAN DEVELOPMENT}

\section{ABSTRACT}

The work is the result of a support and local empowerment prospective and strategic process in 10 municipalities of Norte de Santander, aimed to the identification of their comparative advantages and the proposal of their transformation into competitive advantages in order to formulate sustainable human development sub-regional visions under participatory and inclusive criteria of traditionally segregated groups such as women and youth, through which sub-regional integration spaces to ensure an endogenous and synergistic development of the territory can be possible to configure.

\section{KEYWORDS:}


Participative planning, prospective strategy, sustainable human development, public policies, regional integration.

\section{INTRODUCCIÓN}

La estructura del trabajo refleja el desarrollo de un proceso de generación de dinámicas de integración subregional en Norte de Santander, que se lleva a cabo por parte de la Universidad de Pamplona desde hace varios años y que surge a raíz de la desarticulación municipal y el desequilibrio presente en el territorio departamental. Dicho proceso emerge de una aproximación endógena soportada en herramientas metodológicas de planeación prospectiva y estratégica que permite la caracterización y el diagnóstico de los conflictos socio-ambientales de uso del territorio en diferentes escalas de aproximación, así como de planificación participativa que posibilita valorar como potenciar el sentido de pertenencia y el empoderamiento de los habitantes de diez municipios norte-santandereanos. De esta manera, se logró identificar las ventajas comparativas municipales y generar sinergias para proponer su transformación en ventajas competitivas, por medio de las cuales los municipios objeto de estudio empiezan a configurar espacios de integración subregional para asegurar un desarrollo humano sostenible del territorio.

\section{METODOLOGÍA}

El enfoque sistémico transdisciplinar, la estructura metodológica del proceso prospectivo, estratégico y participativo de desarrollo sostenible se fundamentan en principios orientadores ecológicos y humanísticos, a partir de los cuales, se considera lo ambiental como sistema de soporte de la estructura territorial; lo social como sistema que permite la inclusión equitativa del ser humano en el entorno; lo cultural como sistema que contribuye al reconocimiento de la diversidad; lo político administrativo como sistema de soporte de la gobernabilidad y lo económico como sistema que sustenta la competitividad a escala humana. La articulación sistémica de enfoques y componentes busca el uso adecuado y la apropiación consciente del territorio, como base para la configuración de dinámicas de integración subregional y regional tendientes a asegurar un desarrollo integral del territorio en el nororiente colombiano. 


\section{RESULTADOS Y DISCUSIÓN}

\section{Contextualización}

La propuesta de cooperación para la construcción de visiones de desarrollo sostenible en 10 municipios de Norte de Santander, surge a partir de las dinámicas de gobernabilidad democrática que se desarrollaron en varios municipios de tal departamento, en el marco del programa CERCAPAZ de la Agencia Alemana de Cooperación Técnica-GIZ durante los años 2009-2011, en el que se logró el fortalecimiento de capacidades locales para el logro de mayores niveles de transparencia, eficacia, equidad y participación como condiciones para la construcción de paz. En dichos escenarios, fueron priorizados los conflictos ambientales y la necesidad de un abordaje subregional para la articulación de iniciativas en torno a la gestión de conflictos socio-ambientales.

Teniendo en cuenta los resultados anteriores, la Universidad de Pamplona, en convenio con la Fundación Ecopetrol para el desarrollo de El Catatumbo-Fundescat, procedió a desarrollar el proyecto: "Visiones subregionales de desarrollo sostenible en 10 municipios de Norte de Santander", encaminado a generar alternativas de integración en los municipios de: San Cayetano, El Zulia, Los Patios, Cucutilla, Villa Caro, Arboledas, Salazar, Durania, Cáchira y Labateca, alrededor de la protección del agua. 
Gráfica 1. Municipios Proyecto Unipamplona-Fundescat

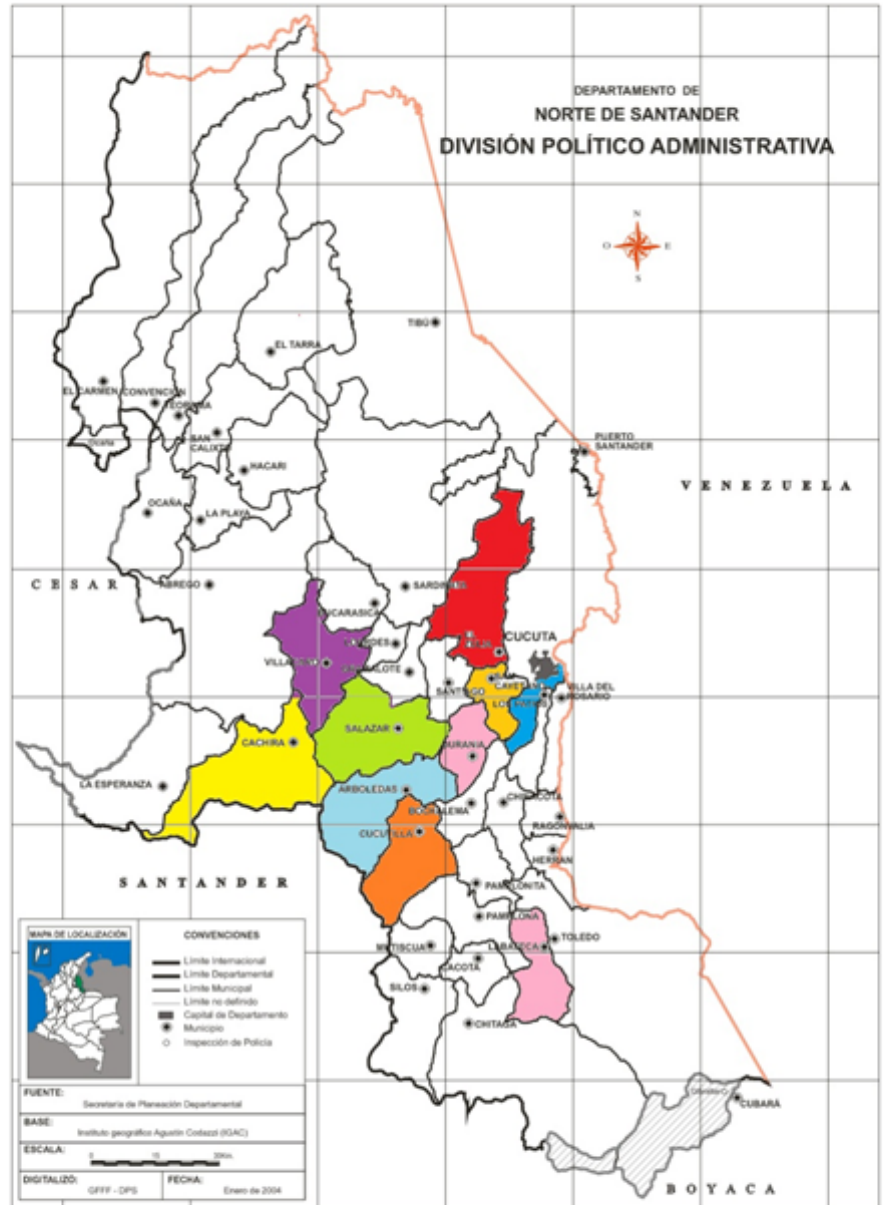

Fuente: Los autores, a partir del mapa de la Secretaria de Planeación Departamental de Norte de Santander y el Instituto Geográfico Agustín Codazzi (IGAC), 2004

Tabla 1. Aspectos básicos del proyecto

\begin{tabular}{|c|c|}
\hline ASPECTOS & DESARROLLO \\
\hline $\begin{array}{l}\text { RESULTADO } \\
\text { DIRECTO }\end{array}$ & $\begin{array}{l}\text { Actores socioambientales del ámbito local y departamental dispuestos a } \\
\text { gestionar recursos para la ejecución de programas y proyectos estratégicos en } \\
\text { torno a visiones subregionales de desarrollo sostenible construidas } \\
\text { participativamente. }\end{array}$ \\
\hline Uso & $\begin{array}{l}\text { Actores socioambientales del ámbito local y departamental inician un proceso } \\
\text { hacia la formulación de unas visiones subregionales de desarrollo sostenible, } \\
\text { atendiendo a criterios de inclusión y equidad. }\end{array}$ \\
\hline LOGROS & $\begin{array}{l}\text { Actores socioambientales del ámbito local y departamental reconocen la } \\
\text { necesidad e importancia de integrarse y asociarse y tienen capacidad para } \\
\text { dialogar, organizarse y acordar una estrategia para avanzar en la construcción y } \\
\text { ejecución de una visión sostenible de desarrollo sostenible en una subregión. }\end{array}$ \\
\hline PRODUCTOS & $\begin{array}{l}\text { Producto 1: Actores socioambientales del ámbito local y departamental } \\
\text { reconocen e intercambien perspectivas sobre dinámicas, conflictos, } \\
\text { oportunidades, actores y recursos en los sistemas social y ambiental del } \\
\text { territorio. } \\
\begin{array}{l}\text { Producto 2: Actores socioambientales del ámbito local y departamental } \\
\text { adquieren conocimientos técnicos, legales y de gestión para adelantar procesos } \\
\text { de integración subregional, bajo principios de sostenibilidad e inclusión. }\end{array}\end{array}$ \\
\hline
\end{tabular}
Fuente: Grupo asesor del proyecto 


\section{Globalización y desarrollo territorial}

La globalización, de acuerdo a Castells $(1999$, p. 2) puede entenderse "como instrumento de articulación de mercados capitalistas, [...] individuos, segmentos de población, países, regiones, ciudades, o barrios, al tiempo que excluyen otros tantos individuos, grupos sociales 0 territorios." En este nuevo modelo de desarrollo informacional que supera a los Estados, pero articula a los segmentos dinámicos de las sociedades en todo el planeta, al tiempo que desconecta y margina socialmente, la sociedad y las instituciones juegan un papel decisivo para asegurar la productividad y la competitividad en torno a proyectos de inversión viables y sustentables (Castells, 1999, p. 3).

La globalización ofrece oportunidades y desafíos para la organización estratégica de los agentes del desarrollo y la productividad en una escala trans-regional, en la que la concertación intermunicipal puede generar consorcios, corredores y microrregiones productivas (Ospina, 2001, p. 31). En América Latina, el papel protagonista de las ciudades se ha venido aclarando en la década de los noventa. Los procesos de democratización, descentralización y modernización del Estado han reforzado la legitimidad e importancia de los gobiernos municipales. La apertura ha movilizado agentes económicos que saben la necesidad de los gobiernos locales por crear condiciones de competitividad y productividad. Sin embargo, también hay una serie de obstáculos para implantar esta visión; aún existen restricciones considerables para ejercer el poder local, el problema de la autonomía no ha sido resuelto; además, los fondos públicos siguen siendo escasos, todavía se están negociando y resolviendo los términos de interacción entre los gobiernos regionales y los nacionales (Borja \&Castells, 1997).

La globalización y las políticas de ajuste que de ella derivan han inducido un nuevo marco macroeconómico, caracterizado por la estabilidad monetaria, el control de la inflación como objetivo prioritario, la liberalización del mercado de capitales, la desregulación económica y la privatización de empresas públicas en casi todos los países. Al mismo tiempo, el desarrollo desigual territorial se ha acentuado y la concentración de población y recursos en las grandes áreas metropolitanas sigue creciendo, suscitando tensiones sociales y deterioro medio-ambiental por falta de control y planeamiento de este proceso de urbanización acelerada, que ha llevado ya a las ciudades al $75 \%$ de la población latinoamericana. (Castells, 1999, p. 7). 
En este contexto, la competitividad debe ser vista como

"la capacidad de un país para sostener y expandir su participación en los mercados internacionales y elevar simultáneamente el nivel de vida de su población. Esto exige el incremento de la productividad $y$, por ende, la incorporación de progreso técnico" (Fajnzylber, 1989, p. 13)

Si bien, los procesos de la globalización acentúan la importancia de las interrelaciones supramunicipales, al mismo tiempo reducen las relaciones locales y agudizan los conflictos multidimensionales en países con débil estructura financiera, procesos de degradación incontrolada de los recursos naturales y de la calidad de vida de sus habitantes (Mosquera, 2006, p. 51).

Como respuesta a la globalización se han generado alternativas de desarrollo encaminadas a la equidad social, a la valoración de la cultura y al fortalecimiento de la conciencia ecológica, las cuales hacen que la polémica se extienda hacia la exploración de las relaciones entre consumo y desarrollo, puesto que algunas perspectivas del primero socavan las oportunidades de un desarrollo sostenible para todos (Rey, 2002).

Desde esta perspectiva, "El desarrollo humano puede entenderse como la generación equitativa de oportunidades para que la población pueda acceder a la educación, la salud, la vivienda, el ingreso, el empleo, como condiciones para su desarrollo personal y cultural" (Bautista, E.; Cesar, citado por Baena Ernesto 2006, p. 1) ${ }^{6}$ y debe estar ligado a un desarrollo sostenible que asegure la satisfacción de las necesidades y aspiraciones del presente sin comprometer las de las futuras generaciones. ${ }^{7}$

Lo anterior denota la necesidad de un enfoque integrador y sistémico que articule, no sólo lo sociocultural y lo ambiental, sino también las potencialidades económicas y políticas del territorio a las necesidades reales de la población, confluyendo en una noción de desarrollo territorial entendida como,

"[...] el conjunto de acciones concertadas para orientar la transformación, ocupación y utilización de los espacios geográficos buscando su desarrollo económico, teniendo en cuenta las necesidades e intereses de la población, las potencialidades del territorio 
considerado y la armonía del medio ambiente" (Fals Borda, 1996, p. 27).

Según Max-Neef et al. (1986) "Si se opta por el supuesto sistémico, la estrategia priorizará la generación de satisfactores endógenos y sinérgicos. Las necesidades serán entendidas simultáneamente como carencias y como potencias, permitiendo así romper con el círculo vicioso de la pobreza." (p.50) y contribuyendo a configurar un escenario de desarrollo territorial en el que "las relaciones de auto-dependencia, por el contrario, tienen mayores efectos sinérgicos y multiplicadores cuando van de abajo hacia arriba" (Max-Neef et al, 1986, p. 59), dentro de un territorio necesariamente descentralizado y de escala territorial y social inicialmente pequeño (Boisier, 2007, p. 83).

En este transcurso, el desarrollo se concibe como fruto de un proceso participativo y perceptivo a las presiones, conflictos socioculturales y desequilibrios socioeconómicos de uso del territorio (MDE a, 1997, p. 10), cuyo direccionamiento está enfocado al empoderamiento local. Por lo tanto, la tarea de

"fomentar la auto-dependencia en múltiples espacios exige considerar el desarrollo ya no como expresión de una clase dominante ni de un proyecto político único en manos del Estado, sino como producto de la diversidad de proyectos individuales y colectivos capaces de potenciarse entre sí. La auto-dependencia implica una especie de regeneración o revitalización a través de los esfuerzos, capacidades y recursos de cada uno" (Max-Neef et al, 1986, p. 61).

Así las cosas,

"se debe concebir el desarrollo como un proceso multidimensional compuesto por grandes transformaciones de las estructuras sociales, de las actitudes de la gente y de las instituciones nacionales, así como por la aceleración del crecimiento económico, la reducción de la desigualdad y la erradicación de la pobreza absoluta". (Todaro \& Smith, citado por Solano, 2007, p. 12).

Concomitante con lo anterior,

“la preocupación técnica central de la teoría del desarrollo será cómo crear en los jóvenes una valoración del hecho de que muchos mundos son posibles, que el 
significado y la realidad son creados y no descubiertos, que la negociación es el arte de construir nuevos significados con los cuales los individuos puedan regular las relaciones entre sí". (Bruner, 1998)

El desarrollo, debe ser integral, es decir que más allá de lo económico contemple aspectos de la persona humana que le permita tener condiciones dignas de realización en lo político, lo social y lo cultural, entre otros. Éste debe entenderse como un fenómeno universal, es decir, que sea alcanzado por todas las personas inmersas en una comunidad. Para hablar de desarrollo, también se debe pensar en sostenibilidad, de tal forma que el sistema económico permita redistribuir los excedentes y así alcanzar condiciones de crecimiento con equidad para todos los pobladores de la región. Finalmente, el desarrollo debe ser solidario, al punto de que quienes gozan de mayores oportunidades compartan con aquellos que por diferentes razones se encuentran excluidos de la sociedad. (Lira, 2007, p. 25)

De acuerdo con lo anterior, se aborda el ordenamiento territorial ambiental "como una modalidad de articulación de los procesos de ocupación y uso del territorio, localización de actividades económicas e infraestructuras de equipamiento con el manejo ambiental" (Méndez, 2000, p. 282), cuyos propósitos son la eficiencia territorial en el gasto y en la inversión, la localización adecuada de las actividades productivas en razón de usos recomendables del territorio y la equidad social articulada a un proceso de distribución espacial del equipamiento de infraestructuras y servicios, a través de la promoción de una oferta de capital social fijo capaz de estimular actividades productivas claves $y$ de mejorar el equipamiento de servicios en las comunidades (Méndez, 2000, p. 283). ${ }^{8}$

Por su lado, las políticas públicas son representaciones de la acción pública que durante buena parte del siglo $X X$ estuvieron centradas únicamente en la acción estatal. En los últimos años, el surgimiento del enfoque de las políticas públicas como una manera de construir la agenda gubernamental, está fuertemente asociado al crecimiento del Estado de Bienestar, así como formas de enlace entre el Estado, el Gobierno y el Ciudadano (López, 2007).

En la relación de integralidad entre el desarrollo y el ordenamiento territorial mencionada anteriormente, las políticas públicas son una puerta de entrada para la interpretación del Estado y de sus relaciones con la sociedad, pues en ellas confluyen el derecho al desarrollo, con el derecho a la vida humana, como derecho 
fundamental de primera generación y con el derecho a un medio ambiente sano, ecológicamente equilibrado, como derecho de tercera generación.

Mosquera y Flórez (2009, p. 68) identifican tres períodos en la política ambiental colombiana. En el primero, el Estado busca su consolidación en el marco de una idea de superioridad del hombre sobre una naturaleza que debe domesticar y puede explotar para lograr el progreso de la civilización; en el segundo, el papel del Estado se traduce en una política intervencionista que afectó a los recursos naturales mediante la búsqueda del aumento de la productividad de los mismos y el desarrollo industrial; en el tercero se evidencia un cambio de valores en el papel Estado, mediante los cuales se considera que éste no es el único actor capaz de hacerse cargo del desarrollo de la sociedad y que los principios para lograr una implementación de políticas públicas más efectivas están relacionados con la participación de la sociedad civil y la subsidiaridad, definidos para la agenda 21 durante la conferencia de Río de Janeiro de 1992 o Primera Cumbre de la Tierra.

En este último período, como lo afirma Roth (2009, pp. 176177), se pretende desarrollar una legislación de "Estado orientador más que de Estado intervencionista", mediante la implementación de unas políticas ambientales descentralizadas, articuladas a las realidades particulares y bajo la responsabilidad de entidades administrativas locales o regionales, en pro del desarrollo sostenible.

Como se puede observar, los nuevos enfoques buscan convertir las políticas públicas;

"[...] en una oportunidad para poner aquellos asuntos claves de las agendas social, económica, ambiental, cultural y política en el terreno de la deliberación pública; ellas deben traducir lo que el Estado y la Sociedad consideran como de interés general, esto requiere involucrar directamente a las organizaciones sociales en la selección de los temas y las estrategias que definen la gestión del desarrollo".(López, 2007).

El enfoque sistémico del desarrollo sostenible. Actualmente, la noción de desarrollo se enmarca en la concepción de territorio, entendido no solamente como un espacio natural, sino también como uno que soporta relaciones ambientales (del ser humano con la naturaleza), 
económicas (de producción), políticas (de poder) y socioculturales (del ser humano con su comunidad y su historia). Según Boisier (1996 citado por Mosquera 2008, p. 281), es precisamente en las dinámicas del desarrollo territorial, donde se articulan las actividades del ser humano y el entorno natural que las soporta y por ello se propone la articulación de básicos: cognitivo, simbólico, cultural, social, institucional, humano; todos ellos contenidos en un espacio. En ese sentido, los procesos de planificación de la estructura territorial deben responder a un enfoque integral de aproximación sinérgica dirigido a proteger y respetar el espacio natural "[...] a partir del uso adecuado y de la apropiación consciente" (Mosquera, 2006, p. 92).

Gráfica 2. Sistema territorial de un territorio organizado

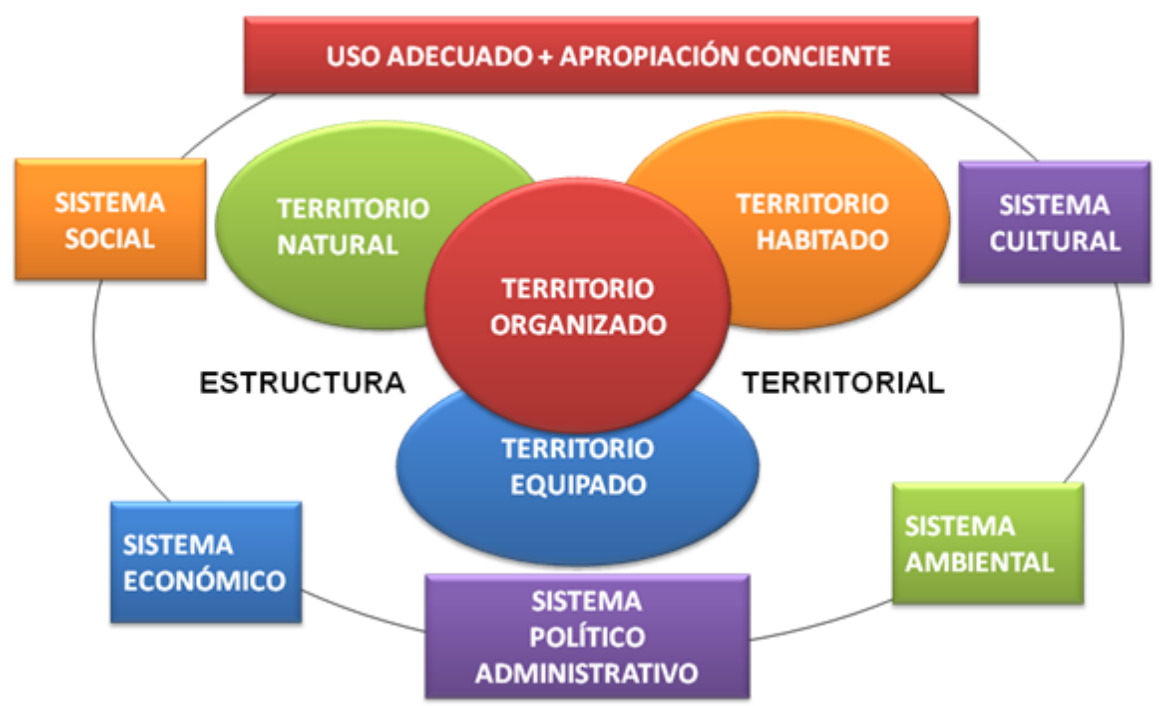

Fuente: grupo GIT

El enfoque conceptual y la estructura metodológica que apropia el grupo de investigación Gestión Integral del Territorio-GIT para el proceso participativo de desarrollo sostenible se fundamenta en principios orientadores ecológicos y humanísticos, mediante los cuales se considera: lo ambiental como sistema de soporte de la estructura territorial basado en la sostenibilidad y la adaptabilidad (López, 2010, p 63); lo social como sistema que permite abordar la interpretación equitativa e incluyente del ser humano en el entorno; lo cultural como sistema que contribuye al "reconocimiento e integración de identidades plurales emergentes de la sociedad" (Castells, 1999, p 15); y lo político administrativo y económico como sistemas de soporte de la gobernabilidad y la competitividad, que desde un carácter contra hegemónico del desarrollo a escala humana (Max Neef, 1986, p 49) facilitan las condiciones 
necesarias para la viabilidad y puesta en marcha de procesos y proyectos en el territorio. La articulación armónica de estos sistemas se convierte en un elemento fundamental para buscar el uso adecuado y la apropiación consciente del territorio además de configurar un desarrollo pacífico desde lo local, en el que se fortalezca la capacidad societal de promover acciones en conjunto dirigidas a fines colectivos y democráticamente aceptados (Boisier, 1996, $p$ $5)$.

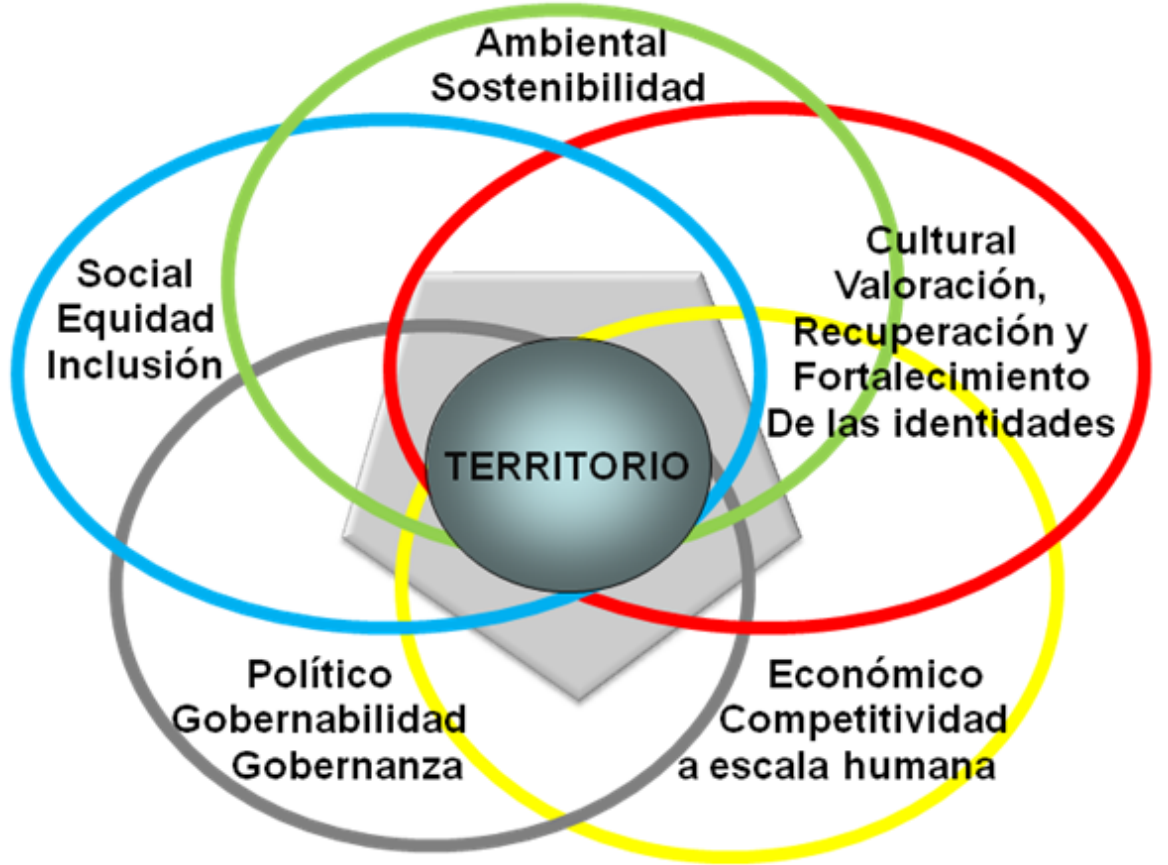

Fuente: Los autores a partir de Mosquera, 2007, p. 9

Como se observa en la Gráfica anterior, el desarrollo integral del territorio se enfoca al cumplimiento de principios sistémicos de sostenibilidad ambiental, equidad social, fortalecimiento de identidades culturales, gobernabilidad democrática y competitividad a escala humana, "reflejados en la tendencia hacia el mejoramiento continuo de las potencialidades humanas de los habitantes; en la formación del capital social, humano e institucional, la educación, el conocimiento y la tecnología" (MDE b, 1997, p 26). La gestión sostenible y la gobernabilidad del proceso se aseguran mediante la concertación de actores sociales, privados y académicos, con los actores políticos que regulan los gobiernos locales en torno a "[...] formas óptimas de uso y manejo de la tierra, considerando las condiciones biofísicas, tecnológicas, sociales, económicas y políticas [...]" (IGAC, 1997, p 25). 


\section{Estructura metodológica.}

La propuesta metodológica se compone de tres fases: Caracterización preliminar, Diagnóstico estratégico (interno y externo) además de Formulación. Teniendo en cuenta los alcances del proyecto, se evidenció la posibilidad de poder avanzar en el año 2011 hasta una etapa inicial de la fase de formulación en la que se planteen, por parte de los actores que participan en el proceso, ejes estructurales y estrategias generales sistémicas (base para la formulación de escenarios prospectivos), de tal manera que en la siguiente etapa del proyecto, sugerida para el año 2012, se pueda continuar con la formulación propiamente dicha de las visiones subregionales y sus estrategias, así como la ejecución o implementación de los resultados obtenidos.

Gráfica 4. Estructura metodológica del proyecto

\section{PLANIFICACIÓN PROSPECTIVA ESTRATEGICA}

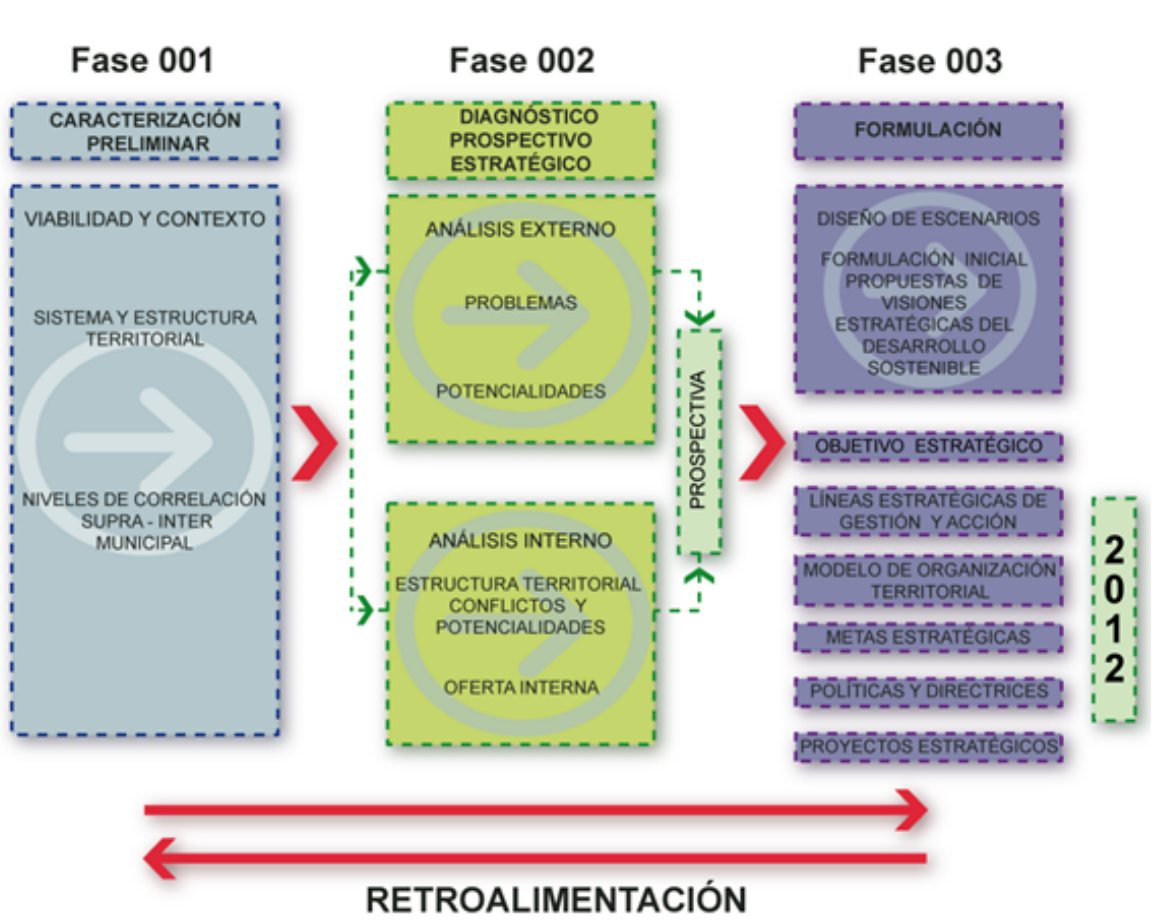

Fuente: Los autores

Dentro de dichas fases se introducen los complementos metodológicos flexibles de participación comunitaria e institucional, teniendo en cuenta las condiciones del territorio, los alcances del proyecto y las limitantes de tiempo. El proceso avanzó sobre una base de retroalimentación permanente con las decisiones obtenidas en las instancias de participación y con la articulación de los diferentes aportes técnicos, académicos, comunitarios e 
institucionales, de tal forma que se lograron resultados coherentes e integrales.

Un elemento a destacar en el proyecto es la estrategia de comunicación para la movilización social, que permitió visibilizar los procesos, resultados y logros en cada fase del proyecto; identificar, promover y facilitar canales para el proceso de integración municipal, asegurar el flujo de la información y construir referentes comunes a partir de las diferencias territoriales e intereses de los distintos actores. Las líneas de acción de la estrategia de comunicación fueron direccionadas a informar, orientar, capacitar y apoyar a las comunidades organizadas, garantizando el derecho a la información y aportando a la gobernabilidad democrática en la construcción de escenarios de inclusión, liderazgo mediador y políticas públicas sostenibles. Las actividades, metodologías y productos relacionados con la documentación del proceso de integración subregional y el uso de herramientas de comunicación, apoyaron la construcción de escenarios de inclusión, participación, liderazgo mediador, procesos alternativos de desarrollo comunicacional y cultural, partiendo de lo local.

Según Montañez y Delgado $(1998$, p.5) El análisis del territorio es indispensable para la comprensión de la estructuración actual, ya que, toda relación social tiene ocurrencia en el territorio y se expresa como territorialidad; éste se concibe como escenario de las relaciones sociales y de dominio soberano de un Estado; es un espacio de poder, de gestión y de dominio de individuos, grupos, organizaciones locales, nacionales y multinacionales y; el mismo no es fijo, sino móvil, mutable y desequilibrado. La realidad geo-social es cambiante y requiere permanentemente nuevas formas de organización territorial.

Fase I. Caracterización preliminar. Se realiza la definición del estado actual del área de estudio mediante la recolección, lectura y análisis de información secundaria como primaria sobre el sistema ambiental y su articulación, desde una perspectiva subregional, con los diferentes sistemas del territorio. La finalidad de caracterizar el territorio consiste en que a partir de la interpretación de sus rasgos fundamentales y su trayectoria histórica se puede conocer los requerimientos de sostenibilidad además de su relación con los principios de equidad, gobernabilidad, territorialidad y competitividad, sobre la cual debe configurarse el desarrollo humano sostenible. El enfoque sistémico del territorio permite la caracterización y evaluación de las fortalezas y debilidades de éste para establecer las tendencias de transformación municipal y 
subregional. Identificación de componentes que definen las características subregionales comunes.

Fase II. Diagnóstico estratégico. Se identifican los niveles de correlación supra e intradepartamental como base para potencializar las dinámicas internas y prerrequisito para aumentar la competitividad territorial de los municipios en el departamento, la región y el país. El trabajo se desarrolla en dos niveles de análisis denominados externo e interno, los cuales sirven para establecer los factores clave que inciden en el territorio y que permiten interpretar sus dinámicas, tendencias, conflictos, oportunidades y amenazas derivadas de acontecimientos externos que afectan al sistema territorial, pero que están fuera de su control.

Gráfica 5. Planeación estratégica

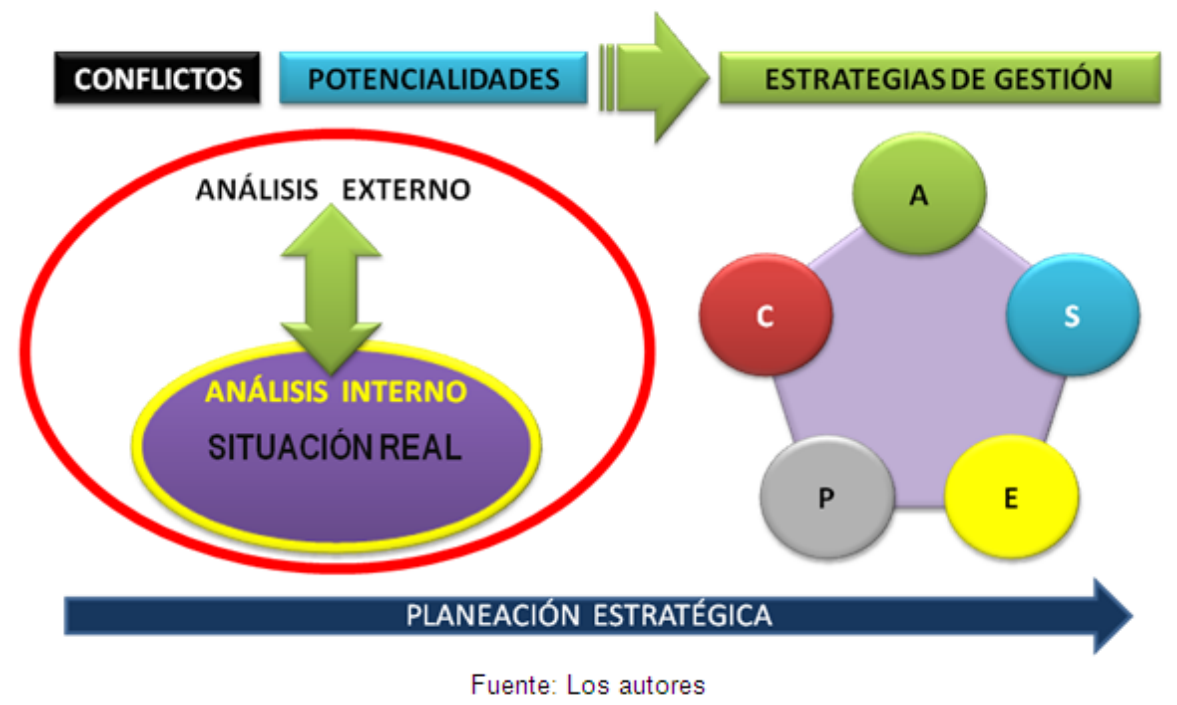

Análisis Externo. Se realiza en el ámbito supradepartamental, sitúa a los municipios en el contexto regional y nacional para así identificar cuáles son las oportunidades externas que fomentan el desarrollo sostenible subregional, asimismo las posibles amenazas que dan marco para establecer cuáles serán las tendencias sostenibles de transformación subregional y departamental.

Análisis Interno. Establece los puntos fuertes y débiles que presentan los municipios objeto de estudio, los niveles de correlación actuales y posibles entre las diferentes dinámicas territoriales municipales y la estructura subregional en relación con el desarrollo sostenible.

Fase III. Formulación. La formulación prospectiva, se da a partir de las tensiones producto de las relaciones de poder en el territorio, de la identificación de la situación real, 
además de la generación de escenarios tendenciales y deseados, los cuales deben articular la tendencia global predominante con las contra-tendencias de poder $y$, de esta manera, posibilitar la definición del escenario posible que servirá de base para el desarrollo de las estrategias generales de intervención y la integración de los municipios en torno al desarrollo sostenible. Dichas estrategias y su implementación, se traducirán físicamente en un modelo territorial sostenible de largo plazo que orientará, tanto la propuesta de organización territorial general, como la formulación de los planes, programas y proyectos estratégicos.

A partir de la generación de escenarios tendenciales, deseados y posibles, se lleva a cabo la formulación concertada de los ejes estratégicos y las estrategias sistémicas de intervención en torno a la conservación y protección de las zonas productoras como receptoras del recurso hídrico. Lo anterior, como prerrequisito para adelantar procesos de integración subregional de desarrollo sostenible en los 10 municipios de norte de Santander, bajo criterios participativos $e$ incluyentes de grupos tradicionalmente segregados como mujeres y jóvenes.

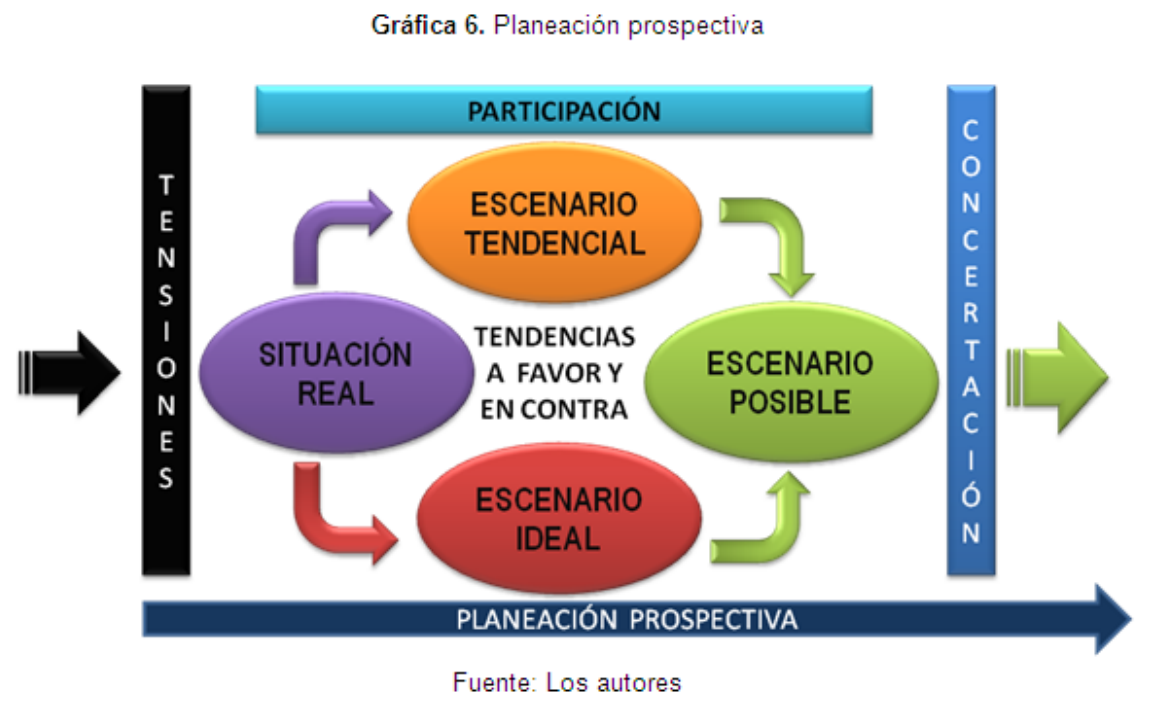

\section{Caracterización territorial de Norte de Santander.}

El análisis regional y subregional implica la rigurosidad de sintetizar el comportamiento de los diferentes sistemas, en esta síntesis es donde toman forma los temas que han estado estructurando el territorio a través del tiempo, y a su 
vez tienen una expresión en la espacialidad, ya sea de manera directa o indirecta.

Norte de Santander posee una superficie de $21.658 \mathrm{Km}^{2}$, cuenta con una ubicación geoestratégica en el contexto nacional, atractivos naturales, culturales y una estructura jerárquica de ciudades que se articula con un sistema policéntrico regional, lo cual le genera una serie de ventajas comparativas que lo han convertido en un centro de servicios.

La ocupación del territorio del departamento de Norte de Santander presenta momentos históricos importantes para el desarrollo nacional, tales como, el cultivo del cacao y la comercialización de harina con alta contribución al producto interno bruto del país. Como respuesta a la crisis económica, en los últimos años ha tomado importancia en el departamento, el sector terciario de venta de servicios y el sector turístico con un enfoque ecológico y agrologico soportado en el respeto por la tierra. 
Gráfica 7. Mapa geográfico de Norte de Santander

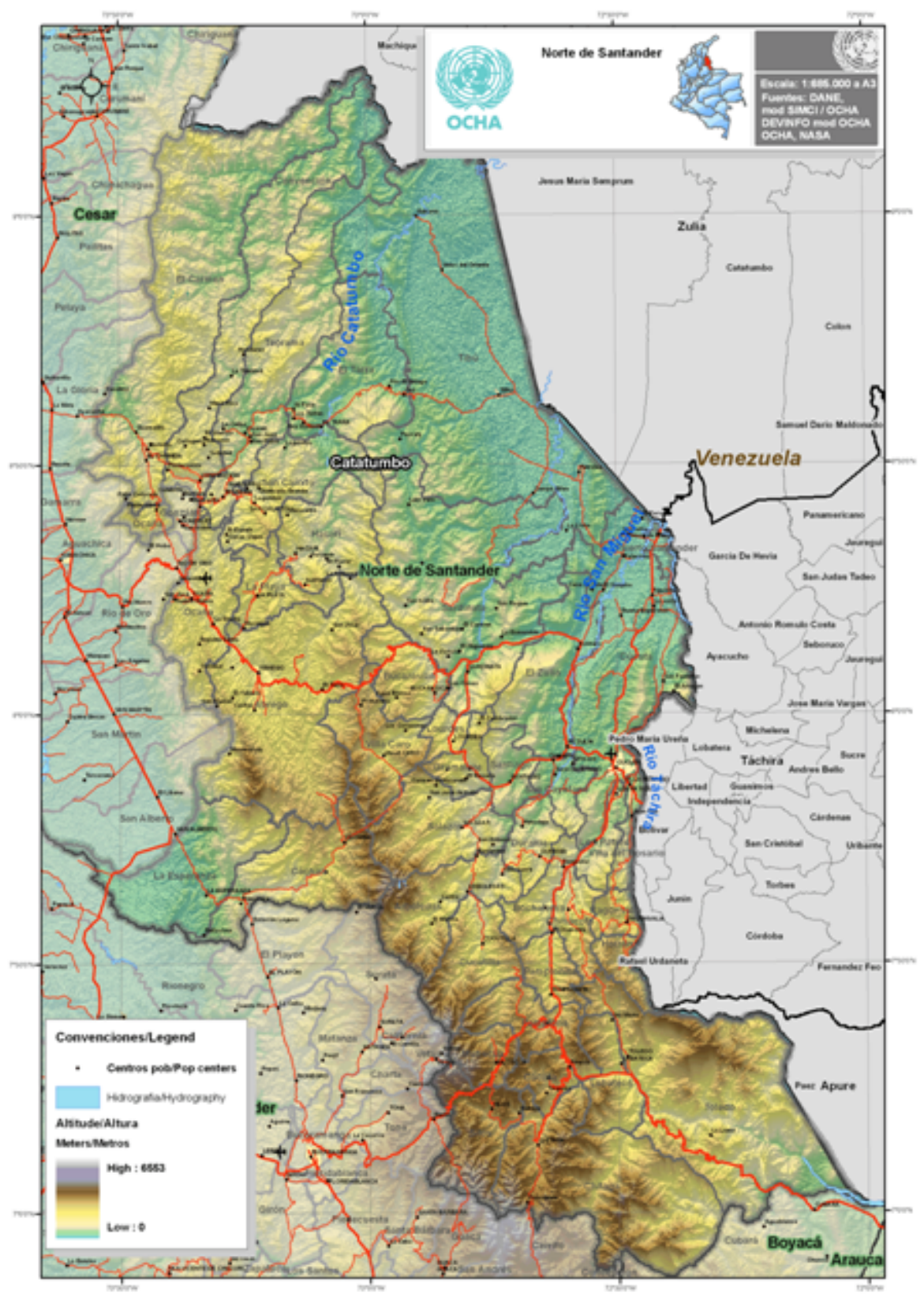

Fuente: DANE, OCHA, NASA

Los Planes, Planes Básicos y Esquemas de Ordenamiento Territorial-POT, PBOT y EOT que todos los municipios de Norte de Santander adoptaron en aplicación de la ley 388/97 como instrumentos básicos para desarrollar el proceso de ordenamiento del territorio municipal, se formularon como un conjunto de acciones políticoadministrativas y de planificación física para disponer de instrumentos eficaces de orientación del desarrollo en el territorio y la regulación de la utilización del espacio físico. Al mismo tiempo, éstos fueron elaborados mediante procesos que, en muchos casos, se caracterizaron por la 
ausencia de recurso humano calificado, la poca sensibilización de las instituciones para apropiar el POT, la baja institucionalidad y una reducida participación ciudadana en el proceso. Lo anterior dio pie a que los POT presentaron desde su formulación fallas técnicas, específicamente en la baja articulación de sus componentes, el desconocimiento de ventajas y necesidades, relaciones o complementariedades (existentes y potenciales) comunes entre municipios vecinos.

Paradójicamente, el departamento cuenta con un gran número de ejercicios de planificación que tratan aspectos económicos de competitividad; sociales, ambientales, e institucionales, en los que se han identificado actores clave, formulado escenarios e interpretado modelos de desarrollo ${ }^{9}$. No obstante, al igual que los POT municipales se han desarrollado de manera desarticulada, mediante enfoques sectoriales, duplicidad de funciones y esfuerzos.

Si bien la posición geoestratégica del Norte de Santander es indiscutible y el potencial endógeno de los municipios está inmerso en cierta autonomía producto del proceso de descentralización que promueve la Constitución Política y la ley 1454 de 2011, a raíz de presentar una inadecuada infraestructura vial, el departamento no ha podido potenciar sus ventajas comparativas en términos económicos de producción, innovación y servicios o como destino turístico nacional. Además, las dinámicas de urbanismo y construcción tradicional, sin planificación ni gestión urbana, hicieron a los municipios altamente vulnerables frente a fenómenos y calamidades naturales. Como consecuencia de lo anterior, los conflictos de uso del territorio han ido ganando espacio y han cambiado las prioridades y el marco de problemas por resolver para cada municipio, lo que necesariamente exige procesos de reinversión económica, del fortalecimiento de la consciencia ambiental y del potencial sociocultural, así como de la optimización de la infraestructura vial y de servicios. 
Tabla 2. Conflictos y ventajas comparativas en Norte de Santander

\begin{tabular}{|l|l|l|}
\hline SISTEMA & \multicolumn{1}{|c|}{ CONFLICTOS } & \multicolumn{1}{c|}{ VENTAJAS COMPARATIVAS } \\
\hline $\begin{array}{l}\text { SISTEMA } \\
\text { AMBIENTAL }\end{array}$ & $\begin{array}{l}\text { Uso inadecuado del territorio, } \\
\text { contaminación y deforestación, manejo } \\
\text { de residuos, vulnerabilidad }\end{array}$ & $\begin{array}{l}\text { Potencial hidrológico, recursos } \\
\text { naturales, políticas ambientales, } \\
\text { políticas frente al riesgo }\end{array}$ \\
\hline $\begin{array}{l}\text { SISTEMA } \\
\text { SOCIAL }\end{array}$ & $\begin{array}{l}\text { Desigualdad, exclusión, conflicto } \\
\text { armado, desplazamiento, necesidades } \\
\text { básicas insatisfechas }\end{array}$ & $\begin{array}{l}\text { Capital humano, políticas incluyentes, } \\
\text { disminución del desempleo }\end{array}$ \\
\hline $\begin{array}{l}\text { SISTEMA } \\
\text { CULTURAL }\end{array}$ & $\begin{array}{l}\text { Escaza valoración de las } \\
\text { manifestaciones culturales y el sentido } \\
\text { de pertenencia }\end{array}$ & $\begin{array}{l}\text { Apoyo a la configuración de espacios y } \\
\text { escenarios para la recuperación y } \\
\text { fortalecimiento de las identidades }\end{array}$ \\
\hline $\begin{array}{l}\text { SISTEMA } \\
\text { ECNOMICO }\end{array}$ & $\begin{array}{l}\text { Bajo aporte al PIB, competitividad } \\
\text { media, desarticulación en la producción, } \\
\text { explotación minera }\end{array}$ & $\begin{array}{l}\text { Regalías, recursos naturales y } \\
\text { prácticas verdes, potencial turístico, } \\
\text { dinámicas comerciales y de servicios }\end{array}$ \\
\hline $\begin{array}{l}\text { SISTEMA } \\
\text { POLiTICO }\end{array}$ & $\begin{array}{l}\text { Centralización, poca autonomía, baja } \\
\text { aplicación de las políticas y normativa } \\
\text { vigente }\end{array}$ & $\begin{array}{l}\text { Nuevas políticas y dinámicas de } \\
\text { descentralización y autonomía, control } \\
\text { social, incentivos }\end{array}$ \\
\hline \multicolumn{2}{|c|}{ Fuente: Los autores, a partir del plan de desarrollo departamental 2008-2011 }
\end{tabular}

Uno de los temas críticos que caracteriza al departamento de Norte de Santander, es la existencia de una marcada desarticulación entre los municipios que lo conforman, los cuales se conciben de manera aislada, sin tener en cuenta las áreas de conurbación con los territorios colindantes, las vocaciones comunes de los suelos suburbanos, ni los vínculos supramunicipales.

Hoy día se hace imprescindible desarrollar dinámicas de ordenamiento territorial departamental y subregional, retomar el proceso de actualización e implementación de los POT municipales con el fin de pasar de la conformación y crecimiento aleatorio de asentamientos y centros urbanos, a un nuevo proceso de planificación de largo plazo, con una dinámica de organización y crecimiento acorde a las nuevas condiciones del entorno regional como del mundo contemporáneo.

Favorablemente, se puede asegurar que en la actualidad existe un ambiente renovador en las instituciones tanto en el ámbito nacional como regional, departamental y local, lo cual genera grandes oportunidades para elegir estrategias adecuadas que permitan dirigir el cambio hacia un desarrollo integral del departamento, teniendo en cuenta los conflictos, potencialidades existentes y las nuevas prioridades del momento. Por lo tanto, es preciso contar con visiones concertadas del territorio, que encaucen la creatividad y los diversos estamentos de la sociedad en la construcción de ese propósito común; y asimismo, sirva para organizar el territorio y promover un desarrollo de acuerdo con las características y ventajas comparativas de Norte de Santander. 


\section{Dinámica de integración subregional para el Desarrollo Humano Sostenible.}

Una labor fundamental en la gestión del territorio es la participación de los actores e instituciones, agentes homogéneos o heterogéneos; la socialización de los informes y resultados y el logro de institucionalidad mediante acuerdos de voluntades para su concreción, participación activa de los actores como adquisición de compromisos por parte de los mismos. En ese sentido, es primordial que la academia tome el liderazgo sobre tales acciones tendientes a consolidar una visión transdisciplinar y sistémica de Norte de Santander, que genere las condiciones para realizar una gestión certera y responsable del desarrollo territorial.

Al respecto, el convenio Unipamplona-Fundescat para la integración subregional es una oportunidad de consolidar el papel protagónico que juega la Universidad de Pamplona en el desarrollo armónico e integral de la región.

Para desarrollar los objetivos y alcances propuestos dentro del proyecto, se llevó a cabo el análisis de información como fuente principal para una investigación de tipo documental llevada a cabo por medio del estudio de los Planes de Desarrollo Municipal 2008-2011 de cada uno de los municipios objeto de estudio; de sus Planes de Ordenamiento Territorial (POT), Planes Básicos de Ordenamiento Territorial (PBOT) y/o Esquemas de Ordenamiento Territorial (EOT); de los datos o indicadores del Censo de 2005 y del Censo de 1993 realizados por el Departamento Administrativo Nacional de Estadística (DANE); de la base de datos desarrollada por la Federación Colombiana de Municipios para la Toma de Decisiones, Formulación, y Monitoreo de los Planes de Desarrollo y Políticas Públicas Locales, y de la Caracterización del Departamento de Norte de Santander realizada por la Secretaría de Planeación Departamental en el año 2009.

Cabe destacar, la escasa información fidedigna, sistematizada y actualizada existente en el departamento, las grandes variaciones de la información que manejan las entidades territoriales nacionales como departamentales, organizaciones privadas y civiles, con relación a temáticas, problemáticas y potencialidades concernientes a los mismos territorios y/o períodos de tiempo. Lo anterior, se convierte en un factor que dificulta el estudio comparativo de variables e indicadores para aspectos y sectores específicos de los municipios objeto de estudio. 
El área de los municipios objeto de estudio corresponde a $3.461 \mathrm{Km}^{2}$, es decir, al $16.1 \%$ del territorio de Norte de Santander. Si bien su territorio no es significativo en términos cuantitativos, su importancia radica en los recursos naturales que serán evidenciados más adelante.

Los municipios objeto de estudio cuentan con páramos, diversidad de pisos térmicos y una gran reserva de recursos naturales, se destaca la presencia de riqueza hídrica y el paisaje. Por su ubicación, se observa que los municipios localizados arriba de 2000 msnm corresponden a los productores del recuso hídrico, mientras que los que se encuentran entre 1000-2000 msnm corresponden a los receptores y protectores del mismo, consecuentemente, los municipios ubicados por debajo de los $1000 \mathrm{msnm}$ corresponden a municipios en su mayoría receptores de tal recurso. Aunque, si bien Cúcuta no hizo parte del presente estudio, se tuvo en cuenta su carácter consumidor para efectos de la socialización de los resultados finales del trabajo, en aras de lograr el compromiso de sus gobernantes respecto a la necesidad de aportar a la conservación de las cuencas en el marco de los derechos colectivos y las responsabilidades compartidas.

La distribución de la población urbana y rural del departamento se caracteriza por la concentración de los habitantes en las ciudades de mayor jerarquía, como por la migración paulatina del campo a la ciudad debido a fenómenos de violencia, desplazamiento forzado y bajas oportunidades de desarrollo del campo.

El desequilibrio en el uso y ocupación del territorio de los municipios objeto de estudio refleja, además, altos porcentajes de necesidades básicas insatisfechas (NBI) que concuerdan con los procesos de planificación centro periferia que priman en Colombia y que repercuten en los departamentos de frontera como Norte de Santander. De igual forma, la vivienda, como elemento fundamental para el desarrollo humano, presenta déficit cuantitativo y cualitativo que atenta contra la calidad de vida de la población exigiendo el direccionamiento de procesos de desarrollo social que pueden ser logrados sobre la base de la asociatividad y la cooperación intermunicipal.

En el diagnóstico estratégico interno del sistema social se identificaron las condiciones actuales de la estructura demográfica, las Necesidades Básicas Insatisfechas (NBI) de la población, los niveles educativos, la infraestructura de servicios, el déficit de vivienda, entre otros elementos, que permitieron determinar algunos conflictos y ventajas comparativas desde diferentes sistemas del territorio en la subregión objeto de estudio. 
Como resultado del estudio de los aspectos ambientales, sociales y culturales, se obtuvo una serie de conflictos y ventajas comparativas, que sirvieron de base para apoyar el trabajo comunitario realizado con representantes de cada uno de los municipios objeto de estudio.

Tabla 3. Conflictos y ventajas comparativas ambientales municipales

\begin{tabular}{|l|l|}
\hline \multicolumn{1}{|c|}{ CONFLIC TOS } & \multicolumn{1}{c|}{ VENTAJAS COMPARATIVAS } \\
\hline $\begin{array}{l}\text { Manejo inadecuado y falta de } \\
\text { protección de las cuencas hídricas }\end{array}$ & $\begin{array}{l}\text { Políticas y herramientas de gestión } \\
\text { territorial y ambiental }\end{array}$ \\
\hline $\begin{array}{l}\text { Ausencia de educación ambiental en la } \\
\text { región }\end{array}$ & $\begin{array}{l}\text { Institutos de educación media, técnica y } \\
\text { superior }\end{array}$ \\
\hline $\begin{array}{l}\text { Apatía social hacia las problemáticas } \\
\text { ambientales }\end{array}$ & $\begin{array}{l}\text { Identidad y consciencia ambiental } \\
\text { municipal }\end{array}$ \\
\hline $\begin{array}{l}\text { Inadecuada explotación de los recursos } \\
\text { mineros }\end{array}$ & $\begin{array}{l}\text { Gestión territorial y ambiental, recursos } \\
\text { naturales - riqueza hídrica }\end{array}$ \\
\hline $\begin{array}{l}\text { Explotación de suelos en áreas } \\
\text { protegidas }\end{array}$ & $\begin{array}{l}\text { Iniciativas municipales para el buen } \\
\text { manejo de los residuos }\end{array}$ \\
\hline $\begin{array}{l}\text { Mal manejo de actividades } \\
\text { agropecuarias }\end{array}$ & $\begin{array}{l}\text { Recursos naturales - riqueza hídrica, } \\
\text { paisajística y buenas prácticas }\end{array}$ \\
\hline
\end{tabular}

Fuente: Los autores

Tabla 4. Conflictos y ventajas comparativas sociales municipales

\begin{tabular}{|l|l|}
\hline \multicolumn{1}{|c|}{ CONFLICTOS } & \multicolumn{1}{c|}{ VENTAJAS COMPARATIVAS } \\
\hline $\begin{array}{l}\text { Personas en NBI 43,6\% de la } \\
\text { población, por encima de Norte de } \\
\text { Santandery Colombia }\end{array}$ & $\begin{array}{l}\text { Comparativamente con Norte de } \\
\text { Santander y Colombia, son menores las } \\
\text { NBI en el área rural, siendo mayor allí el } \\
\text { número de habitantes de 8 municipios } \\
\text { (Durania, Villa Caro, Labateca, Cáchira, } \\
\text { Salazar de las Palmas, Arboledas, San } \\
\text { Cayetano,Cucutilla). }\end{array}$ \\
\hline $\begin{array}{l}\text { Comparativamente, con toda la región } \\
\text { de Norte de Santander y Colombia, es } \\
\text { menor el total de viviendas con } \\
\text { servicios }\end{array}$ & $\begin{array}{l}\text { Alto porcentaje de viviendas con energía } \\
\text { eléctrica y servicio telefónico. }\end{array}$ \\
\hline $\begin{array}{l}\text { Alto porcentaje de personas con ningún } \\
\text { nivel educativo. }\end{array}$ & $\begin{array}{l}\text { Porcentaje alto de personas con nivel } \\
\text { educativo de básica primaria }\end{array}$ \\
\hline $\begin{array}{l}\text { Bajo porcentaje de personas con nivel } \\
\text { educativo superior y media técnica. }\end{array}$ & $\begin{array}{l}\text { Porcentaje considerable de personas con } \\
\text { nivel educativo de secundaria. }\end{array}$ \\
\hline $\begin{array}{l}\text { Alto porcentaje de hogares (54,41\%) } \\
\text { con déficit de vivienda. }\end{array}$ & $\begin{array}{l}\text { El déficit de vivienda cuantitativo } \\
\text { relativamente bajo. }\end{array}$ \\
\hline
\end{tabular}

Fuente: Los autores 
Tabla 5. Conflictos y ventajas comparativas culturales municipales

\begin{tabular}{|l|l|}
\hline \multicolumn{1}{|c|}{ CONFLICTOS } & \multicolumn{1}{c|}{ VENTAJAS COMPARATIVAS } \\
\hline $\begin{array}{l}\text { Pérdida de tradiciones, costumbres y } \\
\text { manifestaciones culturales }\end{array}$ & $\begin{array}{l}\text { Manifestaciones culturales - artísticas, } \\
\text { musicales y artesanales }\end{array}$ \\
\hline $\begin{array}{l}\text { Deterioro de escenarios y edificaciones } \\
\text { patrimoniales }\end{array}$ & $\begin{array}{l}\text { Escenarios culturales y edificaciones } \\
\text { patrimoniales }\end{array}$ \\
\hline $\begin{array}{l}\text { Baja apropiación y valoración del } \\
\text { patrimonio cultural }\end{array}$ & $\begin{array}{l}\text { Festividades y eventos culturales en cada } \\
\text { municipio }\end{array}$ \\
\hline $\begin{array}{l}\text { Baja apropiación y valoración del } \\
\text { patrimonio natural }\end{array}$ & $\begin{array}{l}\text { Recursos naturales - riqueza hídrica, } \\
\text { paisajística y buenas prácticas }\end{array}$ \\
\hline $\begin{array}{l}\text { Poco reconocimiento cultural de los } \\
\text { municipios en el ámbito regional y } \\
\text { nacional }\end{array}$ & $\begin{array}{l}\text { Vocación turística - manifestaciones } \\
\text { culturales, recreativas, religiosas y } \\
\text { gastronómicas }\end{array}$ \\
\hline
\end{tabular}

Fuente: Los autores

Procesos Participativos. Se llevaron a cabo talleres en cada uno de los municipios en los que se dio apertura a espacios incluyentes y se logró identificación de líderes con participación de grupos tradicionalmente segregados, tales como, jóvenes y mujeres. Además, se plantearon dos seminarios-encuentros intermunicipales, cuyo fin fue socializar los resultados obtenidos en los talleres municipales y realizar talleres intermunicipales; avanzar en el proceso de definición de conflictos, además de potencialidades del territorio, formar a los actores, y establecer alternativas como estrategias de integración subregional de desarrollo sostenible

Tabla 6. Resultados obtenidos en el seminario y encuentro del 22 y 23 de octubre de 2011

\begin{tabular}{|c|c|}
\hline OBJETIVOS ESPERADOS & OBJETIVOS LOGRADOS \\
\hline $\begin{array}{lll}\text { Capacitar a los actores en gestión de } \\
\text { problemas } \\
\text { ambientales }\end{array}$ & $\begin{array}{l}\text { Los actores fueron capacitados en gestión de } \\
\text { problemas y potencialidades socioambientales }\end{array}$ \\
\hline $\begin{array}{l}\text { Identificar Ios conflictos y potencialidades } \\
\text { comunes para su gestión colectiva }\end{array}$ & $\begin{array}{l}\text { Se identificaron los conflictos y potencialidades } \\
\text { comunes para su gestión colectiva }\end{array}$ \\
\hline $\begin{array}{l}\text { Identificar potencialidades para la integración } \\
\text { en torno a los conflictos y ventajas comunes } \\
\text { identificadas }\end{array}$ & $\begin{array}{l}\text { Se identificaron las potencialidades para la } \\
\text { integración en torno a los conflictos y ventajas } \\
\text { comunes identificadas }\end{array}$ \\
\hline RESULTADOS ESPERADOS & RESULTADOS OB TENIDOS \\
\hline $\begin{array}{l}\text { Selección participativa de los conflictos y } \\
\text { potencialidades estructurales-sostenibles } \\
\text { comunes }\end{array}$ & $\begin{array}{l}\text { Se realizo la selección, de manera participativa, de } \\
\text { los conflictos y potencialidades estructurales- } \\
\text { sostenibles comunes }\end{array}$ \\
\hline
\end{tabular}

Dentro de los talleres realizados en cada municipio se desarrolló un árbol de problemas detectados por la comunidad. Posteriormente, en el seminario y encuentro se realizó la socialización de éstos, a través de un taller intermunicipal, el cual permitió determinar, en un segundo taller, una matriz síntesis con los conflictos comunes en la subregión. 


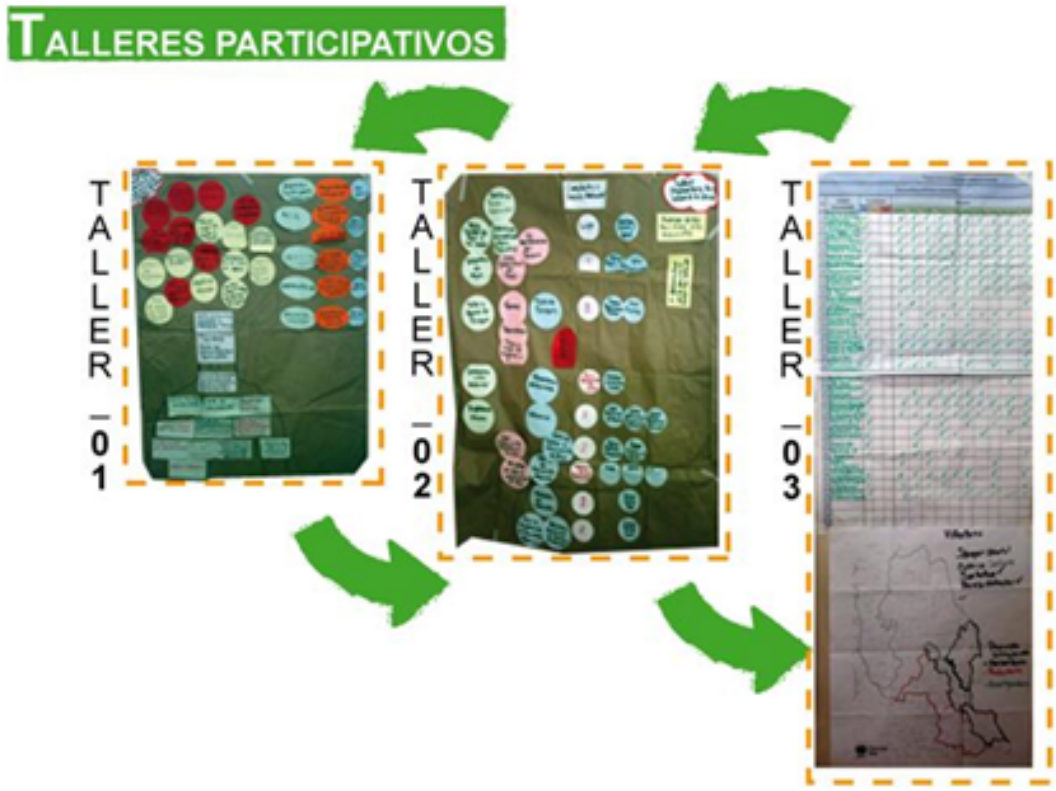

Fuente: Ios autores

Tabla 7. Conflictos de uso del territorio en los municipios objeto de estudio

\begin{tabular}{l}
\begin{tabular}{l|l|}
\hline MUNICIPIOS & CONFLICTOS DE USO DEL TERRITORIO \\
\hline $\begin{array}{l}\text { Cáchira, VillaCaro, Salazar, } \\
\text { Arboledas y Cucutilla } \\
\text { (Páramo de Santurban) }\end{array}$ & $\begin{array}{l}\text { Uso inadecuado del recurso hídrico, ganadería extensiva, } \\
\text { deforestación, mineria ilegal insostenible y manejo inadecuado de } \\
\text { los sistemas productivos. }\end{array}$ \\
\hline $\begin{array}{l}\text { Labateca } \\
\text { (Páramo de Almorzadero) }\end{array}$ & $\begin{array}{l}\text { Mimería ilegal insostenible, escasez y contaminación del recurso } \\
\text { hídrico, ganadería extensiva, deforestación. }\end{array}$ \\
\hline LoS Patios & Baja disponibilidad del recurso hídrico \\
\hline $\begin{array}{l}\text { EIZulia, San Cayetano y } \\
\text { Durania }\end{array}$ & Uso inadecuado y baja disponibilidad del recurso hídrico, \\
\hline
\end{tabular} \\
\hline
\end{tabular}

Paralelamente a los talleres, se realizaron capacitaciones tendientes a la adquisición de conocimientos, por parte de los actores participantes, en gestión de problemas y potencialidades socio-ambientales. Lo anterior, se llevó a cabo a través de aspectos teóricos sobre conflictos de uso, ventajas comparativas y ventajas competitivas para la integración, estrategias como herramientas para convertir ventajas comparativas en competitivas, asimismo casos exitosos de integración. Dichas capacitaciones fueron de gran importancia para el desarrollo del tercer taller en el que se definieron las ventajas comparativas y las potencialidades comunes de la subregión.

Finalmente, se realizó un cuarto taller en el que se determinaron los elementos o aspectos clave (ventajas) para la integración, teniendo en cuenta interrogantes básicos: ¿qué, con quién, cómo y para qué? de dicha integración. 
Gráfica 9. Plenaria para la socialización de resultados grupales

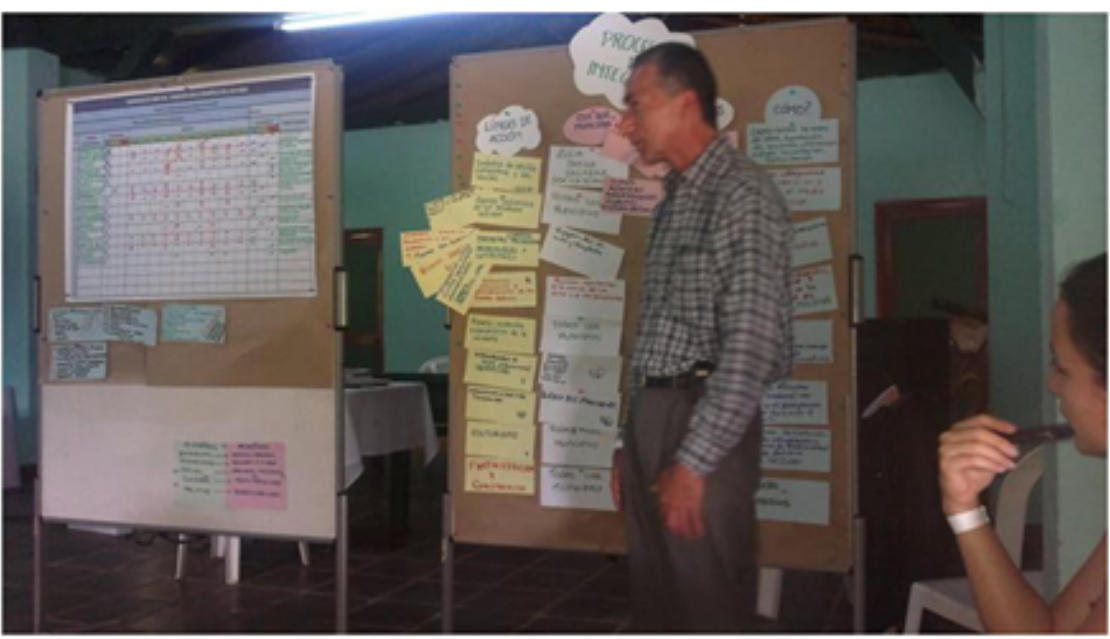

Fuente: Los autores

Los resultados obtenidos en el segundo seminario y encuentro, realizado los días 5 y 6 de diciembre de 2011, permitieron no sólo el cumplimiento de los objetivos propuestos, sino también, la obtención del compromiso de los gobernantes electos en el período 2012-2015 para su inclusión en los procesos administrativos de cada municipio. Dichos resultados, se encuentran enunciados en la siguiente

Tabla 8. Resultados obtenidos en el seminario y encuentro del 5 y 6 de diciembre de 2011

\begin{tabular}{|c|c|}
\hline OBJETIVOS ESPERADOS & OBJETIVOS LOGRADOS \\
\hline Validar el Diagnóstico extemo & Diagnóstico externo validado con los actores sociales \\
\hline $\begin{array}{l}\text { Capacitar a los actores en } \\
\text { construcción colectiva de } \\
\text { escenarios de integración para la } \\
\text { gestión de conflictos ambientales }\end{array}$ & $\begin{array}{l}\text { Actores capacitados en la construcción de escenarios } \\
\text { prospectivos para la gestión de conflictos socioambientales y la } \\
\text { integración territorial }\end{array}$ \\
\hline $\begin{array}{l}\text { Reconocer los posibles } \\
\text { escenarios participativos de } \\
\text { integración territorial }\end{array}$ & $\begin{array}{l}\text { Actores reconocen posibles escenarios participativos y de } \\
\text { integración territorial para la gestión de los conflictos } \\
\text { socioambientales }\end{array}$ \\
\hline RESULTADOS ESPERADOS & RESULTADOS OBTENIDOS \\
\hline $\begin{array}{l}\text { - Interpretar los conflictos y las } \\
\text { potencialidades del territorio, y } \\
\text { reconocer experiencias de } \\
\text { integración para el desarrollo } \\
\text { territorial } \\
\text { - Reconocer los posibles } \\
\text { escenarios para abordar los } \\
\text { conflictos socioambientales y la } \\
\text { necesidad de participar } \\
\text { activamente y articular esfuerzos } \\
\text { para su gestión }\end{array}$ & $\begin{array}{l}\text { - Actores en capacidad de interpretar los conflictos y las } \\
\text { potencialidades del territorio, reconocen experiencias de } \\
\text { integración y su papel en los procesos de integración para el } \\
\text { desarrollo territorial sostenible } \\
\text { - Actores reconocen los posibles escenarios para abordar los } \\
\text { conflictos socioambientales y la necesidad de participar } \\
\text { activamente y articular esfuerzos para su gestión } \\
\text { - Presentación a los alcaldes municipales de la iniciativa del } \\
\text { Acta de Responsabilidad y de la propuesta de Red de Jóvenes } \\
\text { Comunicadores Ambientales } \\
\text { - Compromiso de los alcaldes y delegados para la inclusión de } \\
\text { los resultados obtenidos a la fecha en los dinámicas de } \\
\text { formulación de los Planes de Desarrollo Municipal y los } \\
\text { procesos de revisión y ajuste de los Planes Básicos y } \\
\text { Esquemas de Ordenamiento Territorial. }\end{array}$ \\
\hline
\end{tabular}

En este segundo seminario y encuentro, se socializaron ante la comunidad los resultados de los diagnósticos externos e internos, dejando esbozada la situación actual, los conflictos y potencialidades de la subregión. De igual 
forma, los actores de cada uno de los 10 municipios fueron capacitados en aspectos, tales como, instrumentos de planificación para la integración, construcción de escenarios para abordar los conflictos socio-ambientales y sobre la necesidad de la participación activa de los actores, además de la integración territorial para su gestión.

De la misma manera, se llevó a cabo la socialización de los talleres desarrollados previamente en cada uno de los municipios, a través de la subregionalización por zonas: productoras, protectoras y receptoras del agua, determinando para cada una de éstas sus responsabilidades frente a dicho recurso y las oportunidades para el desarrollo sostenible a partir de la integración.

Gráfica 10. Plenaria para la socialización de resultados

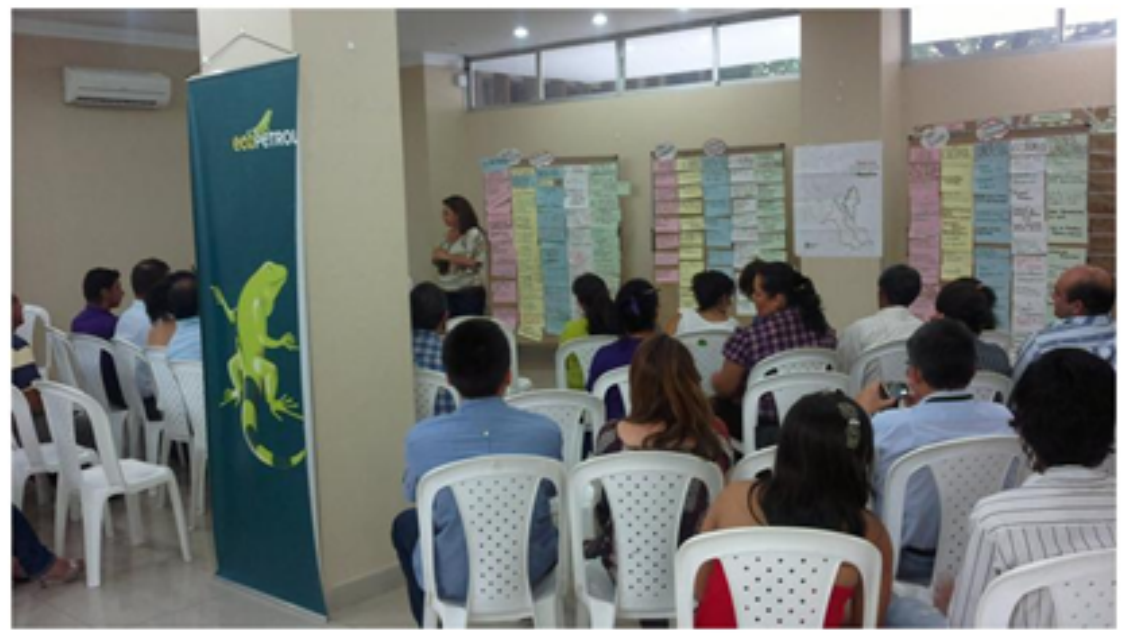

Fuente: Registro fotográfico Jemay Mosquera, 2011

A partir de los resultados del taller desarrollado, se llegó a la consolidación grupal del objetivo de desarrollo, los ejes estructurales y las estrategias de integración, por cada uno de los sistemas del territorio; dicho ejercicio permitió además, reconocer los posibles escenarios de desarrollo territorial para abordar los conflictos socio-ambientales, la necesidad de la participación activa de los actores y de la integración territorial para su solución. 
Tabla 9. Resultados finales del proceso realizado en el 2011

\begin{tabular}{|c|c|c|c|c|c|}
\hline \multirow{2}{*}{$\begin{array}{l}\text { OBJETIVO } \\
\text { COLECTIVO } \\
\text { EJE }\end{array}$} & \multicolumn{5}{|c|}{ INTEGRACION PARA EL MANEJO ADECUADO DEL RECURSO HIDRICO Y LA BIODIVERSIDAD } \\
\hline & SOCIAL & CULTURAL & AMBIENTAL & ECONOMICO & POLITICO \\
\hline $\begin{array}{l}\text { Educación para } \\
\text { una cultura } \\
\text { ambiental }\end{array}$ & $\begin{array}{l}\text { Transversalización } \\
\text { de la educación en } \\
\text { diferentes niveles, } \\
\text { edades, gruposy } \\
\text { sectores }\end{array}$ & $\begin{array}{l}\text { Valoración y } \\
\text { fortalecimiento de } \\
\text { la conciencia } \\
\text { ambiental para el } \\
\text { uso racional de los } \\
\text { recursos }\end{array}$ & $\begin{array}{l}\text { formación } \\
\text { aplicada a la } \\
\text { valoración de las } \\
\text { potencialidades } \\
\text { ambientales } \\
\text { locales }\end{array}$ & $\begin{array}{l}\text { Formación en } \\
\text { ecogestión de la } \\
\text { producción }\end{array}$ & $\begin{array}{l}\text { Fomación para la } \\
\text { gestión pública } \\
\text { sostenible }\end{array}$ \\
\hline $\begin{array}{l}\text { Gobernabilidad } \\
\text { Ambiental }\end{array}$ & $\begin{array}{l}\text { Ciudadania activa e } \\
\text { incluyente }\end{array}$ & $\begin{array}{l}\text { Transparencia. } \\
\text { equidady } \\
\text { corresponsabilidad } \\
\text { en la aplicaciön de } \\
\text { la ley }\end{array}$ & \multirow{2}{*}{$\begin{array}{l}\text { Construcción } \\
\text { colectiva y } \\
\text { adecuada } \\
\text { aplicación de los } \\
\text { instrumentos de } \\
\text { planificación } \\
\text { ambiental }\end{array}$} & \multirow{2}{*}{$\begin{array}{l}\text { Desarrollo de } \\
\text { instrumentos } \\
\text { económicos } \\
\text { Asignación de } \\
\text { rubros en el } \\
\text { presupuesto para } \\
\text { ambiente } \\
\text { Integración } \\
\text { regional y } \\
\text { binacional }\end{array}$} & \multirow[t]{2}{*}{$\begin{array}{l}\text { Desarrollo } \\
\text { institucional y } \\
\text { alianzas } \\
\text { estratégicas para } \\
\text { una gestion } \\
\text { ambiental eficaz }\end{array}$} \\
\hline $\begin{array}{l}\text { Integración } \\
\text { Regional }\end{array}$ & $\begin{array}{l}\text { Red de cooperación } \\
\text { en procesos } \\
\text { sostenibles }\end{array}$ & $\begin{array}{l}\text { Generación de } \\
\text { identidad cultural } \\
\text { regional }\end{array}$ & & & \\
\hline $\begin{array}{l}\text { Sistemas } \\
\text { productivos } \\
\text { sostenibles }\end{array}$ & $\begin{array}{l}\text { Asociatividad para la } \\
\text { producoón } \\
\text { sostenible y a } \\
\text { escala humana }\end{array}$ & $\begin{array}{l}\text { Cultura de la } \\
\text { producción limpia } \\
\text { y la } \\
\text { responsabilidad } \\
\text { socioambiental } \\
\text { empresarial }\end{array}$ & $\begin{array}{l}\text { Práctica de } \\
\text { producción } \\
\text { limpia y un uso } \\
\text { racional de los } \\
\text { recursos }\end{array}$ & $\begin{array}{l}\text { Gestion de } \\
\text { cadenas } \\
\text { productivas } \\
\text { sostenibles } \\
\text { regionales }\end{array}$ & $\begin{array}{l}\text { Incentivos } \\
\text { económicos para la } \\
\text { gestión productiva } \\
\text { de bienes y } \\
\text { servicios sostenibles }\end{array}$ \\
\hline $\begin{array}{l}\text { Desarrollo de } \\
\text { turismo } \\
\text { sostenible }\end{array}$ & $\begin{array}{l}\text { Fomento del turismo } \\
\text { comunitario }\end{array}$ & $\begin{array}{l}\text { Trabajar el turismo } \\
\text { con el patrimonio } \\
\text { cultural e histórico } \\
\text { tangible e } \\
\text { intangible }\end{array}$ & $\begin{array}{l}\text { Planificación y } \\
\text { promoción del } \\
\text { turismo en la } \\
\text { naturaleza }\end{array}$ & $\begin{array}{l}\text { Adecuación de la } \\
\text { infraestructura } \\
\text { turistica. } \\
\text { Conformación y } \\
\text { fortalecimiento de } \\
\text { mipymes }\end{array}$ & $\begin{array}{l}\text { Anticulación de las } \\
\text { instituciones } \\
\text { públicas y privadas } \\
\text { del turismo. } \\
\text { Integración cultural }\end{array}$ \\
\hline $\begin{array}{l}\text { Cienciay } \\
\text { Tecnologia para } \\
\text { el } \\
\text { aprovechamiento } \\
\text { sostenible }\end{array}$ & $\begin{array}{l}\text { Red de } \\
\text { conocimiento } \\
\text { cientifico sobre el } \\
\text { territorio }\end{array}$ & $\begin{array}{l}\text { Implementación } \\
\text { de tecnologias } \\
\text { apropiadasy } \\
\text { aplicadas }\end{array}$ & $\begin{array}{l}\text { Nodo cientifico } \\
\text { del agua y la } \\
\text { biodiversidad }\end{array}$ & $\begin{array}{l}\text { Apropiación de } \\
\text { nuevas } \\
\text { tecnologias para } \\
\text { la gestión de } \\
\text { proyectos } \\
\text { productivos }\end{array}$ & $\begin{array}{l}\text { Apoyoa la } \\
\text { producción y } \\
\text { difusión de } \\
\text { conocimiento } \\
\text { cientifico }\end{array}$ \\
\hline
\end{tabular}

Finalmente, en el encuentro se presentó ante algunos de los alcaldes electos, representantes de la nueva administración departamental y delegados para la inclusión, los resultados obtenidos hasta la fecha y se obtuvo el compromiso de los gobernantes de continuar y liderar el proyecto de integración subregional mediante dinámicas relacionadas con la inclusión de los resultados del proceso en la formulación de los Planes de Desarrollo Municipal 2012 - 2015 y en los procesos de revisión y ajuste de los Planes Básicos y Esquemas de Ordenamiento Territorial Municipales. Así mismo, los jóvenes participantes presentaron y firmaron un acta de responsabilidad alrededor de la conservación del agua y el establecimiento de la red de jóvenes comunicadores ambientales. 
Gráfica 11. Entrega a los Alcaldes electos del Acta de Responsabilidad y de la propuesta de Red de Jóvenes Comunicadores Ambientales

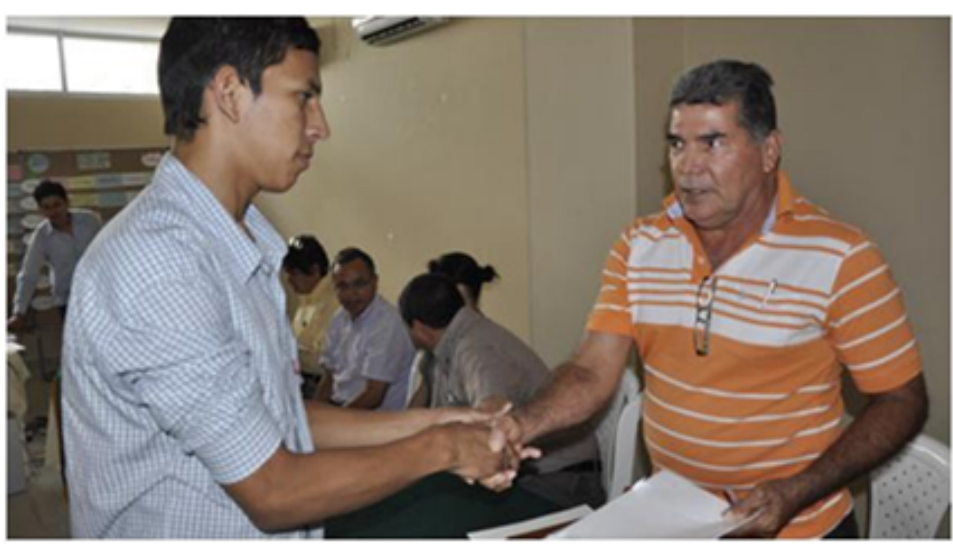

Fuente: equipo de comunicación del proyecto

Tomando como base los resultados del proceso adelantado en el año 2011 alrededor de la conservación y el uso adecuado del agua, se pretende continuar en el 2012 para establecer las visiones de integración subregional para el desarrollo sostenible, las cuales se definirán a partir de los escenarios tendenciales, deseados y posibles, así como de las estrategias generales de intervención. Por medio de dichas visiones será posible la integración de los municipios en torno a la conservación y protección de las zonas productoras y receptoras del recurso hídrico. Su implementación, se traducirá físicamente en un modelo territorial sostenible de largo plazo, que orientará, tanto la propuesta de organización territorial de integración subregional, como la formulación de planes, programas y proyectos estratégicos.

\section{CONCLUSIONES}

Los procesos externos producto de la globalización y los conflictos al interior de las regiones, contribuyen al aumento de la segmentación territorial y de la complejidad de las estructuras urbanas. Por lo tanto, el principal reto de la globalización es evitar una fragmentación de los territorios nacionales, ello obliga a un tratamiento individual, pero unificado, que aproveche el papel estratégico de las localidades dentro de las transformaciones funcionales y espaciales surtidas en la era de la información y del conocimiento ,las cuales deberán ir de la mano con lo ambiental, estableciendo así un concepto de desarrollo enfocado hacia la sostenibilidad y sustentabilidad, desde la oferta ambiental, bajo la óptica de obtener rendimientos estables, es decir, una productividad básica, de acuerdo a la capacidad que pueden suministrar los ecosistemas. 
Dicha oferta depende del contexto desde el que se aborda la interpretación del territorio, o sea, desde las interrelaciones de uso y apropiación consciente local-global y/o global-local.

La reformulación de la integración territorial supone la configuración de una gobernabilidad de diferentes niveles en el marco de espacios sub-nacionales, transfronterizos y/o transnacionales. Por esta razón, independiente del contexto general de relaciones de centro-periferia, se plantea la necesidad de pasar a la acción a partir de proyectos específicos de articulación comunitaria, de proyectos asociativos, del aprovechamiento de las múltiples formas de cooperación y de la participación de las universidades en los procesos de integración, conformación y consolidación de redes de conocimiento encaminadas a asegurar procesos de regionalización y desfronterización basados en la estructuración de espacios sub-nacionales, transfronterizos como transnacionales.

En el contexto de la globalización, la noción de desarrollo sostenible exige una concepción integradora y transdisciplinar que va más allá de las relaciones económicas y políticas, abarcando cambios estructurales en los sistemas, políticos, económicos, sociales, culturales y ambientales. Esta noción sistémica debe valorar y fortalecer el papel del ser humano como sujeto histórico transformador de su entorno, igualmente enfocar los esfuerzos a configurar su apropiación consciente y el uso adecuado del territorio en contextos espaciales y temporales que abarcan diferentes escalas de aproximación al territorio.

Uno de los aspectos críticos que caracteriza al departamento de Norte de Santander es la existencia de una marcada desarticulación entre los municipios que lo conforman, los cuales se conciben de manera aislada e independientes, sin tener en cuenta las áreas de integración con los territorios colindantes, las disposiciones comunes de los suelos suburbanos, ni los vínculos supramunicipales, regionales o binacionales. Se debe entonces, interpretar sus rasgos fundamentales y su trayectoria histórica en cuanto a gobernabilidad, sostenibilidad, sustentabilidad, equidad, territorialidad y competitividad, principios sobre los cuales debe pensarse un desarrollo humano territorial sostenible apto para la planificación y gestión estratégica de proyectos de integración regional.

Es necesario dejar de lado la proyección de los municipios norte santandereanos como entes territoriales independientes, enfocando los esfuerzos hacia su 
articulación e integración regional, estableciendo participativamente un modelo de desarrollo territorial sostenible, con políticas y estrategias que permitan promover el empoderamiento local como el fortalecimiento de capacidades de asociatividad, educación, cultura, ambiente, turismo sostenible y producción verde, en las que lo local-global se articule con lo global-local, y sirva de base para la concreción de procesos de desarrollo sostenible con igualdad social, bienestar y calidad de vida para las presentes y futuras generaciones.

Es evidente la necesidad de fomentar la gestión local de estudios y proyectos multidimensionales e interinstitucionales, que influyan en los niveles jerárquicos superiores y modifiquen, mediante la democratización del conocimiento, la forma de gobierno, el proceso de toma de decisiones y el funcionamiento de las instituciones. Tales estudios deben integrar los conocimientos tradicionales y los actores sociales a los estudios científicos; es desde abajo que la Universidad de Pamplona, conjuntamente con la administración pública, el sector privado, la comunidad y la participación de profesionales comprometidos con la transformación del hábitat, podrá asumir un rol protagónico que le permita realizar una gestión acertada de los ecosistemas para elevar el nivel de vida de las comunidades regionales, generando nuevas posibilidades de desarrollo sostenible en las que lo local-global se articule con lo global-local, al concretar procesos de desarrollo humano con igualdad social, bienestar y calidad de vida para las presentes y futuras generaciones.

Las políticas públicas y las dinámicas de integración subregional de desarrollo sostenible se deben basar en la perspectiva de gobernabilidad, de respeto por los recursos naturales, de construcción de ciudadanía, de fortalecimiento de identidades y sentido de pertenencia hacia el territorio subregional y departamental, concebido éste como un sistema dinámico, en proceso de estructuración y permanente evolución (la historia crea identidades y pertenencia y le confiere permanencia al territorio) y no como el resultado de intervenciones particulares y aisladas de cada uno de sus municipios.

\section{BIBLIOGRAFÍA}

- Baena, E. (2006). Algunos Factores Indispensables para Logro del Desarrollo Regional. 1. 
- Bautista, C. (1996). La Región: Discursos y Hechos. En, Risaralda: Desafíos del Desarrollo. Fundación Espiral, Fondo editorial de Risaralda, Pereira, Colombia.

- Boisier, S. (1996). El desarrollo territorial a partir de la construcción de capital sinergético. En: Estudios Sociales Número 99, CPU. Santiago de Chile. p.20

- Boisier, S. (2007). Territorio, estado y sociedad en Chile. La dialéctica de la descentralización: entre la geografía y la gobernabilidad. Universidad de Alcalá, España, p. 339

- Borja, J. \& Castells, M. (1997). Local and Global. The Management of Cities in the Information Age United Nations Center for Human Settlements (Habitat). London: Earthscan Publications Ltd. ISBN-10: 1853834416. p. 288

- Bruner, J. (1988). "La teoría del desarrollo como cultura". En: Realidad mental y mundos posibles. Barcelona: Gedisa.

- Castells, M. (1999). Globalización, identidad y Estado en América Latina. Ministerio Secretaría General de la Presidencia y PNUD. Santiago de Chile. p.18

- Fajnzylber F. (1989). Industrialización en América Latina, de la "caja negra" al "casillero vacío". p. 13

- Fals Borda, O. (1996). Región e Historia: elementos sobre ordenamiento y equilibrio regional en Colombia. (1 ed.). Bogotá: Tercer Mundo Editores-IEPRI, U. Nacional. p. 27

- IGAC. (1997). Bases conceptuales y guía metodológica para la formulación del plan de ordenamiento territorial departamental. IGAC-Ministerio de Hacienda y Crédito Público. ISBN 9589067344. Bogotá. p. 350

- Lira, J. (2007). Universidad y Desarrollo Regional. Instituto de Estudios Social Cristianos Konrad Adenauer Stiftung. p.25

- López, M. H. (2007). El asunto de las políticas públicas. Revista Luna Azul ISSN 1909-2474, Universidad de Caldas, Manizales,

Desde:http://lunazul.ucaldas.edu.co/index.php?option=conte nt\&task=view\&id=330

- López-Bernal, O. (2010). Planeamiento urbano sostenible para la adaptación al cambio climático. Estudios de caso Canadá-Colombia. ISBN 978-958-670-789-3. Cali: Editorial Universidad del Valle. p. 162

- Max Neef, M.; Elizalde, A. y Hopenhayn, M. (1986). Desarrollo a Escala Humana -Una Opción para el FuturoCEPAUR. Santiago de Chile. p. 96

- Méndez, E. (2000). Ordenamiento territorial-ambiental: desarrollo responsable y sostenible. Revista geográfica venezolana, Vol 41 (2). Mérida. pp. 281-301

- Ministerio de Desarrollo Económico-MDE a. (1997). Ministerio de Desarrollo Económico. Procesos de aplicación. Criterios para desarrollar planes departamentales de ordenamiento territorial. Bogotá. pp. 9-26.

- Ministerio de Desarrollo Económico-MDE b. (1997). Lineamientos para el ordenamiento territorial departamental. (1 ed.). Bogotá. pp. 24-26. 
- Montañez-Gómez G y Delgado Maecha O. (1998). Espacio, territorio y región. p. 122 , p. 5

- Mosquera, J. (2006). Arquitectura y Desarrollo. Revista científica UNET. ISBN 1316- 869X11C. Volumen 18, Número 2. Universidad Nacional Experimental del Táchira. San Cristóbal, Venezuela. pp. 47-46.

- Mosquera, J. (2007). Patrimonio Cultural y Desarrollo Territorial. Revista M. Universidad Santo Tomas. Bucaramanga. ISSN 1692-5114. Vol.4 Número 1, pp. 4-13

- Mosquera, J. (2008). El paisaje cultural y la territorialidad en la gestión sostenible y la gobernabilidad del territorio. Memorias III Congreso de patrimonio cultural y cooperación al desarrollo. Muñoz Cosme \& Vidal Lorenzo Editores. ISBN 978-84-482-4898-7. México, pp. 279-287

- Mosquera J.\& Flórez C. (2009). Naturaleza, políticas públicas y derechos humanos-hacia una concepción legal de la relación ser humano-naturaleza. Revista Nova et Vetera, Escuela Superior de Administración Pública-ESAP. Bogotá. Volumen 19, Número 1. ISSN 0123-2614, pp. 6778

- Mota, L. (2002). El capital social: un paradigma en el actual debate sobre el desarrollo. Tendencias y problemas. Espiral, Estudio sobre estado y sociedad. ISSN 1665-0565, Vol. 9 Número 25, septiembre-diciembre, pp. 37-65

- Ospina, S. (2001). Globalización y desarrollo local: hacia una perspectiva municipalista. En: revista de estudios sociales. Universidad de los Andes. ISSN (versión en línea):1900-5180. 21-34 pp. Desde: http://res.uniandes.edu.co/view.php/171/view.php.

- Rey, G. (2002). "Cultura y Desarrollo Humano: Unas relaciones que se trasladan" en Pensar Iberoamérica. Revista de cultura de la Organización de Estados Americanos (OEI), Barcelona, 2002. Artículo 4. Extraído el 29 de agosto de 2011. Desde:http://www.oei.es/pensariberoamerica/ric00a04.htm

- Roth-Deubel, A.N. (Ed.), Políticas públicas, Formulación, implementación y evaluación, $6^{a}$ Ed., Bogotá, Ed. Aurora, ISBN 978-958-913-615-x, pp. 232

- Todaro\& Smith citado por Solano, D. (2007). Desarrollo, Sostenibilidad y Capacidades. Una trilogía indesligable. p.12.

1. Artículo de reflexión derivada de investigación relacionada con la planeación prospectiva estratégica. Hace parte de los procesos participativos adelantados en el marco del proyecto de interacción social: "Visiones subregionales de desarrollo sostenible" (2011) y el proyecto de investigación:"Dinámicas de integración subregional para el desarrollo humano sostenible en Norte de Santander"(2012)", desarrollados en el grupo de 
investigación: Gestión Integral del Territorio: GIT, de la Universidad de Pamplona.

2. M.Sc. en Hábitat. Codirectora del grupo de investigación: Gestión Integral del Territorio-GIT, de la Universidad de Pamplona.

3. Ph.D. en Arquitectura. Profesor asociado y director del grupo de investigación: Gestión Integral del Territorio-GIT, de la Universidad de Pamplona.

4. Arquitecto. Profesor tiempo completo ocasional y miembro del grupo de investigación Gestión Integral del TerritorioGIT, de la Universidad de Pamplona.

5. Estudios de maestría en Gestión Urbana. Profesor tiempo completo ocasional y miembro del grupo de investigación Gestión Integral del Territorio-GIT, de la Universidad de Pamplona.

6. La idea de desarrollo humano elaborada por el Programa de las Naciones Unidades para el Desarrollo PNUD "[...] consiste en el aumento de las capacidades de la gente a partir de la ampliación de sus funciones y opciones para vivir de acuerdo con sus valores" (Informe Regional de Desarrollo Humano IRDH, 2004). Si bien, esta noción incorpora, además del crecimiento del PIB, otros indicadores enfocados a una mejora en la calidad de vida (en áreas como la salud y la educación, la infraestructura básica y vivienda, los derechos humanos y el respeto por el medio ambiente y la atención de las políticas sociales), no tiene en cuenta indicadores intangibles que articulen la relación entre la satisfacción de necesidades humanas, la calidad de vida y la naturaleza, en una percepción estética y sensible del ser humano por el ambiente (Mosquera, 2006, p. 50)

7. Trabajo de la Comisión Mundial sobre Medio Ambiente y Desarrollo, denominado Nuestro Futuro Común o Informe de Brundtland, 1987.

8. Según Mota (2002), la discusión que se lleva a cabo durante los últimos 15 años parte del postulado de que los seres humanos no son sólo un medio del desarrollo, sino su fin último y por lo tanto, se ha planteado la necesidad de acompañar el crecimiento económico con desarrollo social equitativo, democrático y sostenible, en el marco de la ampliación de las oportunidades reales de las personas para desenvolver sus potencialidades.

9. Lo anterior resalta el liderazgo del sector público representado por el ejecutivo en el ámbito territorial e indica que se está consolidando una cultura de pensamiento de largo plazo, en donde la sociedad civil del departamento y de la región participa activamente. 